\title{
Gender Differences in the Associations Among Body Mass Index, Weight Loss, Exercise, and Drinking Among College Students
}

Adam E. Barry PhD

Shawn Whiteman PhD

Anna K. Piazza-Gardner MS

Alexander C. Jensen PhD

Brigham Young University, alexjensen@byu.edu

Follow this and additional works at: https://scholarsarchive.byu.edu/facpub

Part of the Psychology Commons

\section{Original Publication Citation}

Adam E. Barry PhD , Shawn Whiteman PhD , Anna K. Piazza-Gardner MS \& Alexander C. Jensen PhD (2013) Gender Differences in the Associations Among Body Mass Index, Weight Loss, Exercise, and Drinking Among College Students, Journal of American College Health, 61:7, 407-413, DOI: 10.1080/07448481.2013.823973

\section{BYU ScholarsArchive Citation}

Barry, Adam E. PhD; Whiteman, Shawn PhD; Piazza-Gardner, Anna K. MS; and Jensen, Alexander C. PhD, "Gender Differences in the Associations Among Body Mass Index, Weight Loss, Exercise, and Drinking Among College Students" (2013). Faculty Publications. 3526.

https://scholarsarchive.byu.edu/facpub/3526

This Peer-Reviewed Article is brought to you for free and open access by BYU ScholarsArchive. It has been accepted for inclusion in Faculty Publications by an authorized administrator of BYU ScholarsArchive. For more information, please contact ellen_amatangelo@byu.edu. 


\title{
Gender Differences in the Associations Among Body Mass Index, Weight Loss, Exercise, and Drinking Among College Students
}

\author{
Adam E. Barry PhD , Shawn Whiteman PhD , Anna K. Piazza-Gardner MS \& \\ Alexander C. Jensen PhD
}

To cite this article: Adam E. Barry PhD , Shawn Whiteman PhD , Anna K. Piazza-Gardner MS \& Alexander C. Jensen PhD (2013) Gender Differences in the Associations Among Body Mass Index, Weight Loss, Exercise, and Drinking Among College Students, Journal of American College Health, 61:7, 407-413, DOI: $10.1080 / 07448481.2013 .823973$

To link to this article: https://doi.org/10.1080/07448481.2013.823973

Accepted author version posted online: 15

Jul 2013.

Published online: 06 Sep 2013.

Submit your article to this journal $₫$

Џll Article views: 1184

Q View related articles $\square$

Citing articles: 23 View citing articles 4 


\title{
Gender Differences in the Associations Among Body Mass Index, Weight Loss, Exercise, and Drinking Among College Students
}

\author{
Adam E. Barry, PhD; Shawn Whiteman, PhD; Anna K. Piazza-Gardner, MS; \\ Alexander C. Jensen, PhD
}

\begin{abstract}
Objective: To explore gender differences regarding weight management behaviors of college drinkers. Participants: Nationally representative sample of college students from the fall 2008 American College Health Association's National College Health Assessment II ( $N=26,062$ students). Methods: Structural equation modeling was used to examine potential gender differences in associations among exercise, weight loss behaviors, and alcohol use. Results: Critical ratio tests revealed that associations between exercise and weight loss behaviors were more strongly correlated among females as compared with males. For females, there was a small negative association between exercise and drinking behaviors; in contrast, for males, there was a positive relationship between exercise and alcohol use. Weight loss behaviors were positively associated with drinking for both female and male students; however, the association was significantly stronger for females. Conclusions: This investigation furthers previous research on drunkorexia and also sheds additional light on the gender-based differences in weight management behaviors of drinkers.
\end{abstract}

Keywords: alcohol, college students, drunkorexia, exercise, gender, weight loss

or decades, alcohol use, abuse, and dependence have exhibited a well-documented comorbid relationship with disordered eating behaviors and diagnoses (eg, unhealthy weight control practices, diet-related behaviors, anorexia, bulimia) among females. ${ }^{1,2}$ In fact, severity of alcohol use was identified as a significant predictor of mortality

Dr Barry and Ms Piazza-Gardner are with the Department of Health Education and Behavior at the University of Florida in Gainesville, Florida. Dr Whiteman and Dr Jensen are with the Department of Human Development and Family Studies at Purdue University in West Lafayette, Indiana.

Copyright @ 2013 Taylor \& Francis Group, LLC in females diagnosed (Diagnostic and Statistical Manual of Mental Disorders Fourth Edition criteria) with anorexia nervosa. ${ }^{3}$ The co-occurrence of these behaviors and diagnoses has been repeatedly documented among collegiate females as well. ${ }^{4-6}$ To date, however, there is limited literature examining this co-occurrence among collegiate females and males. Among the few investigations examining both male and female college students, disordered eating and diet-related behaviors were found to co-occur with alcohol use/abuse among both groups. ${ }^{7,8}$

Qualitatively examining the interrelationship between alcohol use and diet-related behaviors among 78 college students, Peralta ${ }^{8(\mathrm{p} 37)}$ suggests that "a number of women and men ... express sufficient anxiety over caloric content of alcohol to engage in diet-related behaviors of varying severity." Moreover, 39\% of college students (both male and female) who have consumed alcohol within the past 30 days report restricting food, fat, and/or calories on days they planned to drink alcohol. ${ }^{9}$ Investigations have found no significant differences between males and females in regards to reasons for restricting calories prior to drinking, which range from avoiding weight gain to enhancing alcohol's effects. $^{10}$

\section{Drunkorexia}

Although it is known that alcohol use and eating behaviors exhibit a clear association, there is currently an emerging literature base that links these behaviors to other (nondietary) weight control practices such as exercise. ${ }^{11,12}$ Within the context of consuming alcohol-related calories, both male and female college student drinkers report (proactively and reactively) engaging in exercise and dietary restriction. ${ }^{12,13}$ 
Among a nationally representative sample of college students, both exercise (eg, vigorous exercise, strength training) and unhealthy weight management behaviors (eg, vomit or use laxative to lose weight, use diet pills to lose weight) significantly predicted binge drinking status, even after controlling for age, gender, Greek member status, race, year in school, and type of residence. ${ }^{11}$ Dubbed "drunkorexia" by the lay press, ${ }^{14,15}$ this nonmedical colloquial term characterizes "weight-conscious drinkers" who enact compensatory behaviors such as caloric restriction and/or purging (including excessive exercise) to offset consumed alcohol-related calories. Unfortunately, our understanding of drunkorexia is limited by the lack of scholarly investigations fleshing out the relationship among these 3 behaviors (alcohol use, exercise, and dietary weight control strategies). In addition, only 1 study has investigated gender differences in relation to weight management behaviors of drinkers. ${ }^{8}$ To account for these limitations, the current investigation explored the directional effects of these behaviors using structural equation modeling. Specifically, we sought to determine associations among indirectly measured latent variables of exercise, weight loss behaviors, and alcohol consumption among a nationally representative sample of college students. Consistent with previous work, ${ }^{11-13}$ we hypothesize that exercise and weight loss behaviors each will be positively associated with alcohol consumption. We build on this work, however, by further exploring whether the associations among these constructs are the same for men and women. Previous literature has identified females as more likely to decrease food intake in relation to alcohol consumption compared with males ${ }^{8}$; thus, we hypothesize that decreased caloric intake/disordered eating will be more closely linked to females as opposed to males. The methodology of this study was informed by previous investigations examining the interrelatedness of alcohol consumption, physical activity, and disordered eating among college students. ${ }^{11}$

\section{METHODS}

\section{Instrument and Procedures}

Items included in the 2008 American College Health Association's National College Health Assessment II ${ }^{16}$ (ACHANCHA II) were utilized in this investigation. The ACHANCHA II represents an ideal survey instrument for investigating the college student population, as it provides a plethora of information on college student health behaviors (ie, sexual activity, diet and physical activity, mental health, and alcohol/illicit substance abuse). Self-selected institutions administer the survey typically in the Fall and/or Spring semester. Schools are responsible for using random sampling techniques to obtain subjects, followed by Web-based and/or classroom-based (paper form) surveying. Upon completion of the survey, the ACHA scans and analyzes deidentifed, aggregate data to create executive summaries, reference group reports, and data sets that are relayed back to each participating institution.

\section{Measures}

\section{Weight Loss}

Because weight loss efforts take many forms, weight loss was measured as a latent variable. Using a yes/no response format, respondents were asked to report on 4 different weight loss behaviors: (a) "Within the last 30 days, did you exercise to lose weight?" (48\% no; $51 \%$ yes); (b) "Within the last 30 days, did you diet to lose weight?" (64\% no; $35 \%$ yes); (c) "Within the last 30 days, did you vomit or take laxatives to lose weight?" (96\% no; 3\% yes); and (d) "Within the last 30 days, did you take diet pills to lose weight?" (96\% no; $3 \%$ yes).

\section{Exercise}

Given its multidimensional nature, exercise was also measured as a latent variable and included 3 indicators: (a) moderate-intensity activity ("On how many of the past 7 days did you do moderate-intensity cardio or aerobic exercise (causing a noticeable increase in heart rate, such as a brisk walk) for at least 30 minutes?"); (b) vigorous-intensity activity ("On how many of the past 7 days did you do vigorousintensity cardio or aerobic exercise (causing large increases in breathing or heart rate, such as jogging) for at least 20 minutes?"); and (c) strength training ("On how many of the past 7 days did you do 8-10 strength-training exercises (such as resistance weight machines) for 8-12 repetitions each?"). Responses for each of these items ranged from 0 to 7 days.

\section{Alcohol Consumption/Drinking}

Because alcohol consumption is a multifaceted behavior comprising several types of alcohol use, respondent alcoholrelated behavior was assessed as a latent variable, including items addressing one's frequency and quantity of consumption, as well as binge drinking behavior. The item "Over the last 2 weeks, how many times have you had 5 or more drinks of alcohol at a sitting?" was utilized to determine one's binge drinking status. Response options included "none" to "10 or more times," as well as "N/A, don't drink." Frequency of drinking was based on the item "Within the last 30 days, on how many days did you use alcohol?" Responses included never used, have used but not in last 30 days, 1-2 days, 3-5 days, 6-9 days, 10-19 days, 20-29 days, and use daily. Lastly, quantity of alcohol consumption was assessed via the item "The last time you "partied"/socialized how many drinks of alcohol did you have?" Responses indicated a number from 0 (if they did not drink alcohol) to 99.

\section{Controls}

Three control variables were included in the model to account for potential confounding effects; they included ethnicity, Greek status, and body mass index (BMI). Ethnicity was included as a control based on prior research identifying the highest rates of alcohol consumption among white college students, compared with peers of other ethnic backgrounds. ${ }^{17}$ Greek (ie, fraternity and sorority) status was also included as a control, as Greek members tend to differ in their 
alcohol-related behaviors (eg, consume alcohol in greater quantities, are at greater risk for negative alcohol-related consequences, and emulate a culture in which alcohol is a central component of the socialization process). ${ }^{18}$ Previous research has also highlighted various associations between BMI and exercise, ${ }^{19,20}$ as well as BMI and weight control behaviors $^{21,22}$; therefore, BMI was also included as a control variable. BMI was calculated from students' self-reported heights and weights.

\section{Analytic Strategy}

We used structural equation modeling (SEM) to examine potential gender differences in associations among exercise, weight loss behaviors, and alcohol use during college. This modeling strategy was advantageous, as SEM procedures are flexible and can handle both continuous and categorical/count data. ${ }^{23,24}$ Models were estimated using AMOS 20 (SPSS, Chicago, Illinois). Several indices were used to assess model fit, including the $\chi^{2}$ statistic, the comparative fit index (CFI), and root mean square error of approximation (RMSEA). According to Hu and Bentler, ${ }^{25}$ good model fit is defined by an RMSEA of .06 or less and CFI greater than or equal to .95 . Given that actual cutoff criteria vary as a function of models used, these authors and others ${ }^{26}$ note that the evaluation of model fit is best determined by the convergence of several fit indices.

\section{RESULTS}

The final sample for this investigation was composed of 26,062 students (18,107 females and 7,955 males) from 40 campuses throughout the United States (ie, Fall 2008 NCHA reference group). The majority of participants were white $(71 \%)$ and not members of a Greek organization (91\%). The sample institutions varied according to (a) private/public status, (b) size of the student body (ranging from fewer than 2,500 to 20,000 or more students), (c) degree offerings (ie, 2- or 4-year programs, graduate and/or undergraduate degrees), (d) geographic location throughout the United States; (e) religious affiliation (eg, secular, Catholic, Protestant), and (f) minority status (eg, historically African American college, Hispanic-serving institution). Of the 40 participating institutions, $88 \%(n=35)$ used the ACHA-NCHA Web version and $12 \%(n=5)$ used the ACHA-NCHA paper form version of the survey.

Respondents reported an average of 3.42 days of moderate $(S D=2.08), 2.66$ days of vigorous $(S D=1.90)$, and 2.18 days of strength-training $(S D=1.69)$ exercise over the past 7 days. On average, subjects consumed $3.4(S D=4.08)$ alcoholic beverages the last time they "partied"/socialized. Mean BMI $\left(\mathrm{kg} / \mathrm{m}^{2}\right)$ for females was $23.91(S D=5.27)$ and $24.58(S D=4.68)$ for males.

An initial measurement model was first estimated to determine whether the latent measures of alcohol use, exercise, and weight loss behaviors demonstrated adequate model fit. For identification purposes, 1 item for each factor was constrained to be equal to 1 and factor structures were constrained to be equal across gender. Correlations among each of the 3 factors were also estimated. The measurement model revealed good fit, $\chi^{2}(d f=71)=2792.52$, CFI $=.96$, nonnormed fit index $=.93$, RMSEA $=.04$. Factor loadings are presented in Table 1.

As can be seen in Figure 1, the structural model examined the associations among exercise, weight loss, and alcohol use, controlling for the known associations among ethnicity, Greek status, and alcohol use. ${ }^{17,18}$ BMI was also included as a correlate of both exercise and weight loss behaviors ${ }^{19-21}$ as well as a predictor of drinking behaviors. Given gender differences in the associations among exercise, ${ }^{13,27}$ weight loss, ${ }^{8,28}$ and $\mathrm{BMI},{ }^{29,30}$ associations among these variables were tested to determine if they varied across groups. Associations between Greek status and alcohol use as well as ethnicity and alcohol use, however, were constrained to be equal across genders. Potential gender differences in the associations among exercise, weight loss behaviors, BMI, and alcohol use were tested using multigroup tests. Specifically, models were tested by estimating 2 models: (a) coefficients

TABLE 1. Factor Loadings for Latent Variables Indexing Exercise, Weight Loss, and Alcohol Use $(N=26,062)$

\begin{tabular}{llcc}
\hline \hline Factor & \multicolumn{1}{c}{ Item } & $\begin{array}{c}\text { Unstandardized factor } \\
\text { loading }\end{array}$ & $\begin{array}{c}\text { Standardized factor } \\
\text { loading (female/male) }\end{array}$ \\
\hline Exercise & Moderate-intensity activity & 1.00 & $.67 / .71$ \\
& Vigorous-intensity activity & $1.18^{*}$ & $.87 / .92$ \\
Weight loss & Strength training & $0.75^{*}$ & $.68 / .60$ \\
& Exercise to lose weight & 1.00 & $.74 / .69$ \\
& Diet to lose weight & $0.85^{*}$ & $.63 / .69$ \\
Alcohol use & Use pills to lose weight & $0.12^{*}$ & $.14 / .27$ \\
& Vomit to lose weight & $0.07^{*}$ & $.22 / .29$ \\
& Quantity of drinks & 1.00 & $.80 / .76$ \\
& Frequency of drinking & $0.48^{*}$ & $.72 / .88$ \\
& Binge drinking & $0.52^{*}$ & $.87 / .83$ \\
\hline
\end{tabular}

Note. Paths were constrained to be equal for females and males. Standardized estimates vary, however, because AMOS 20 uses within-group variances to calculate standardized estimates.

${ }^{*} p<.001$. 


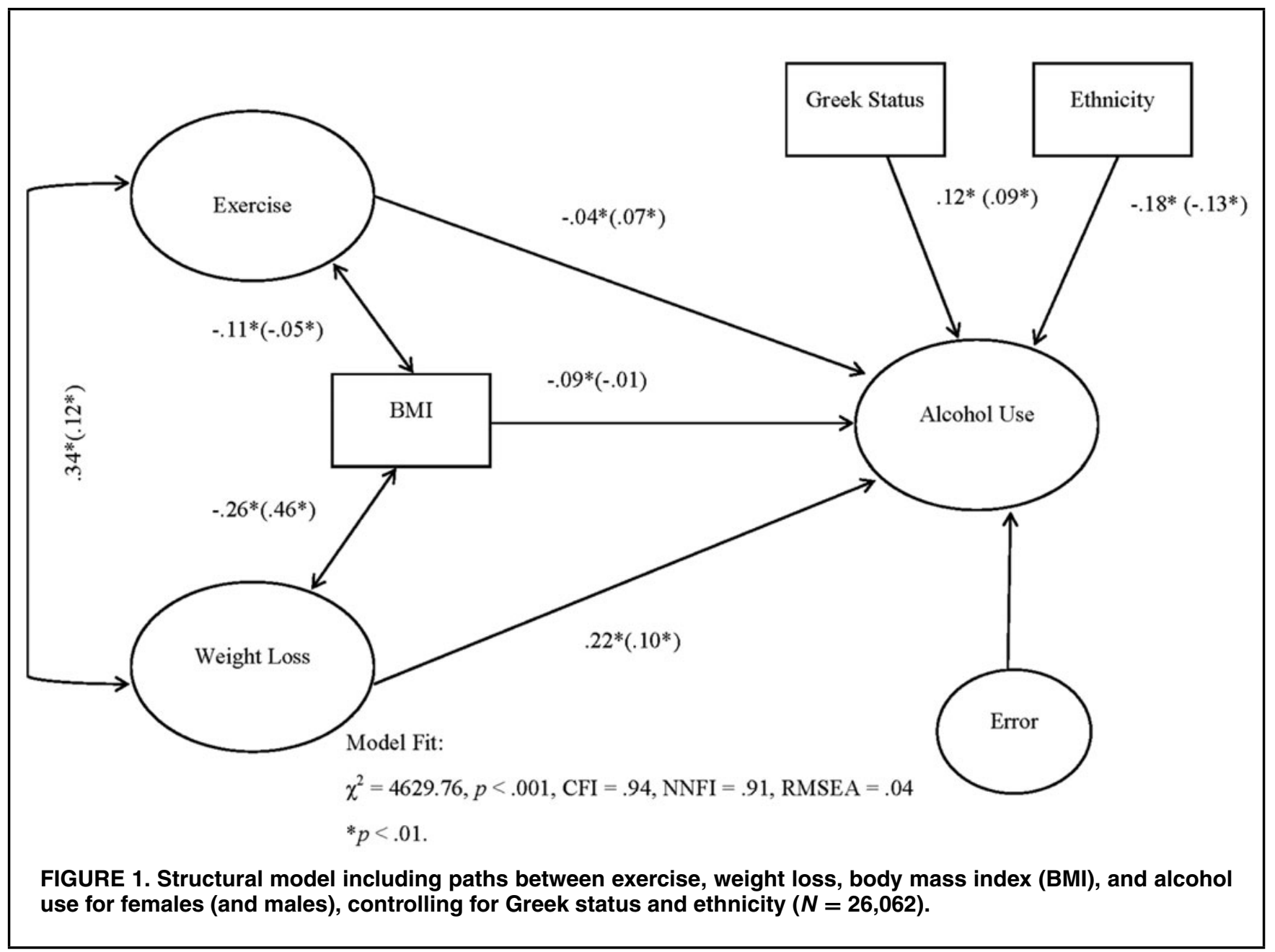

constrained to being equal across groups (ie, male and female); and (b) coefficients varied across groups. Follow-up $\chi^{2}$ tests were used to determine whether the latter model, reflecting moderation effects, resulted in improved model fit over the constrained model. If gender differences were detected, critical ratios were calculated to test gender differences for specific pathways.

The constrained model revealed adequate model fit, $\chi^{2}(d f=135)=4887.42$, CFI $=.94$, Tucker-Lewis index $=.91$, RMSEA $=.04$. Multigroup tests, however, revealed that the unconstrained model resulted in improved fit, $\chi^{2}(d f$ $=6)=257.67, p<.001$, indicating gender differences in the associations among BMI, weight loss, exercise, and drinking. Critical ratio tests revealed that associations between exercise and weight loss behaviors were more strongly correlated among females $(r=.34, p<.001)$ as compared with males $(r=.12, p<.001) ; z=11.31, p<.001$. Exercise was negatively linked to BMI for both males $(r=-.05, p<.001)$ and females $(r=-.11, p<.001)$; however, the association was stronger for females $(z=3.71, p<.001)$. Weight loss behaviors were positively linked to BMI for both male $(r=.46, p$ $<.001)$ and female $(r=.26, p<.001)$ students; however, the correlation was stronger for males $(z=7.87, p<.001)$.
With respect to students' alcohol use, critical ratio tests revealed gender differences in the paths between exercise and drinking $(z=6.63, p<.001)$, weight loss and drinking $(z=2.42, p<.01)$, and BMI and drinking $(z=2.80, p<.01)$. For females, there was a small negative association between exercise and drinking behaviors $(b=-.08, S E=.02, \beta=$ $-.04, p<.001)$; in contrast, for males, there was a positive relationship between exercise and alcohol use $(b=.15, S E=$ $.03, \beta=.07, p<.001)$. Weight loss behaviors were positively associated with drinking for both female $(b=1.54, S E=.08$, $\beta=.22, p<.001)$ and male $(b=1.04, S E=.18, \beta=.10$, $p<.001)$ students; however, the association was significantly stronger for females. Finally, BMI was negatively related to female students' drinking behaviors $(b=-.04, S E=.004$, $\beta=-.09, p<.001)$, but unrelated to male students' alcohol use $(b=-.01, S E=.01, \beta=-.01, n s)$. Figure 1 presents the standardized estimates for all estimated pathways separately for males and females.

\section{COMMENT}

The findings of this investigation highlight gender differences in the associations among BMI, weight loss, exercise, and drinking among college students. Overall, both 
males and females were likely to exercise for weight loss, and weight loss behaviors (ie, exercise, purging, restricting calories) were positively associated with alcohol consumption. Although we cannot determine causality, our analyses using SEM do suggest that males may be more likely to exercise due to alcohol consumption (evidenced by the positive correlation between exercise and drinking), whereas females may tend to exercise less as a result of alcohol consumption (evidenced by negative correlation between exercise and drinking). Furthermore, BMI was negatively linked to exercise and positively linked to weight loss for both genders; however, BMI was negatively related to drinking only among females.

A stronger association between exercise and weight loss behavior for females compared with males is likely due to the fact that weight loss is more common among females, whereas males tend to be more preoccupied with gaining muscle and losing fat. ${ }^{30-32}$ For instance, male sentiments regarding body image and weight typically include "having larger arms" and "having a 'V'-shaped body," ${ }^{33}$ whereas female sentiments include "I don't want to be fat" and "I'm not a muscle head." ${ }^{8}$ These ideals likely stem from the mainstream culture of a "thin ideal" for females ${ }^{34-36}$ and masculine/muscular ideal for males. ${ }^{37-39}$

The positive association between weight loss and alcohol consumption for both genders aligns with previous research identifying both male and female college student drinkers (proactively and reactively) engage in exercise and dietary restriction to offset calories from drinking. ${ }^{12,13}$ However, the results of this study suggest potential gender differences in the primary means used for weight loss/maintenance. Evidenced by the positive association between exercise and drinking, males tend to use exercise to manage weight in the presence of alcohol consumption, whereas females may tend to use alternative methods for weight loss/maintenance such as skipping meals and purging (evidenced by the negative association between exercise and drinking). This finding echoes previous research identifying males as more likely to negate caloric intake with exercise, whereas females are more likely to restrict food intake and vomit. ${ }^{13,26}$

In addition, the observed positive association between alcohol use and weight loss is likely tied to the association between alcohol and body dissatisfaction/disordered eating. Previous research supports the link between one's alcohol consumption and disordered eating behaviors ${ }^{9,40,41}$ - a relationship that exists among those clinically diagnosed with an eating disorder, as well as those exhibiting problematic eating and weight control practices. ${ }^{5,42}$ Positive associations between body dissatisfaction and alcohol use/abuse have also been observed among both males and females. ${ }^{43,44}$ Therefore, body dissatisfaction may represent a potential moderator in the relationship between weight loss behaviors and alcohol consumption among male and female college students.

The observed positive association between weight loss and BMI for both genders is also consistent with prior research. ${ }^{45-47}$ Body dissatisfaction represents a plausible explanation for this relationship, as extant scientific literature has identified a positive relationship between BMI and body dissatisfaction. ${ }^{46,48}$ Likewise, weight loss behavior (eg, dietary restriction, vomiting/purging, use of diet pills) and body dissatisfaction are highly correlated as well. ${ }^{49-51}$ A lack of gender differences in the interrelatedness of BMI, weight loss, and body dissatisfaction comes as no surprise, considering that although body dissatisfaction was once identified as more common among females, ${ }^{52,53}$ recent research has identified males are just as dissatisfied with their bodies. ${ }^{27,54}$ It is important to note, however, that this investigation did not assess body dissatisfaction.

The aforementioned findings are of practical significance to college health practitioners. The interplay of alcohol use/abuse, disordered eating, and exercise may be of practical significance to mental health professionals. For instance, students presenting with an alcohol abuse issue may need to be screened for disordered eating as well. Professionals should also consider gender differences in body dissatisfaction and methods used for weight control. Likewise, the use of exercise to assist in treating disordered eating or alcohol abuse may not be appropriate. The design and implementation of prevention programs and policies should consider the various gender differences in weight control behaviors, specifically within the context of drinking. For example, advertisements related to safer drinking practices (ie, not drinking on an empty stomach, not using alcohol to purge) should target female students, whereas messages related to body dissatisfaction, exercise, and alcohol should target male students.

\section{Limitations}

Although the results of this study offer new and timely findings that fill current gaps in the scientific literature, there are also several limitations that are noteworthy. Since this investigation employed secondary data, the limitations associated with the original NCHA, such as (a) the self-report nature of the data, (b) self-selection of institutions, and (c) reliance on ACHA member institutions, are consequently inherited. Despite the large sample of subjects and diverse institutions, these limitations prevent us from being able to generalize to all college students. Like all other secondary analyses, we were also constrained by the manner in which our independent (weight loss, exercise) and dependent (alcohol) variables were operationalized and measured. Along those same lines, it is important to note that the recall time frame for these measures ranged from the last 7 days to the last 30 days. Thus, it is possible the behaviors being measured did not occur within the same timeframe. As a result, it is possible we did not fully capture the essence of the behaviors we were attempting to analyze. For example, assessing other facets of alcohol consumption such as whether typically done alone or in a social setting may have helped frame the behavior as it actually occurs among students.

\section{Conclusions}

The current research represents one of the few investigations examining the association between alcohol use and 
disordered eating among a large, nationally representative sample of college males and females. Moreover, to the best of our knowledge, this investigation represents the first attempt to systematically assess (together) the links among alcohol use, exercise, and dietary weight control strategies. Results of this study further previous research on drunkorexia $^{11,12}$ and also shed additional light on the gender-based differences in weight management behaviors of drinkers. ${ }^{8}$ Still, additional research is warranted to identify valid and reliable measures that best encompass the co-occurrence of alcohol use, disordered eating, and exercise among college students. Use of such measures would subsequently enhance our understanding of the prevalence and magnitude of this phenomenon, lending credibility to the design and implementation of campus programming efforts.

\section{ROLE OF FUNDING SOURCES DISCLOSURE}

No funding was used to support this research and/or the preparation of the manuscript.

\section{CONFLICT OF INTEREST DISCLOSURE}

The authors have no conflicts of interest to report. The authors confirm that the research presented in this article did not require institutional review board approval.

\section{NOTE}

For comments and further information, address correspondence to Adam E. Barry, Department of Health Education and Behavior, University of Florida, PO Box 118210, Gainesville, FL 32611, USA (e-mail: aebarry@ufl.edu).

\section{REFERENCES}

1. Gadalla T, Piran N. Co-occurrence of eating disorders and alcohol use disorders in women: a meta-analysis. Arch Womens Ment Health. 2007;10:133-140.

2. Grilo CM, Sinha R, O'Malley SS. Eating disorders and alcohol use disorders. Alcohol Res Health. 2002;26:151-160.

3. Keel PK, Dorer DJ, Eddy KT, Franko D, Charatan DL, Herzog DB. Predictors of mortality in eating disorders. Arch Gen Psychiatry. 2003;60:179-183.

4. Anderson DA, Martens MP, Cimini MD. Do female college students who purge report greater alcohol use and negative alcoholrelated consequences? Int J Eat Disord. 2005;37:65-68.

5. Krahn DD, Kurth CL, Gomberg E, Drewnowski A. Pathological dieting and alcohol use in college women-a continuum of behaviors. Eat Behav. 2005;6:43-52.

6. Luce KH, Engler PA, Crowther JH. Eating disorders and alcohol use: group differences in consumption rates and drinking motives. Eat Behav. 2007;8:177-184.

7. Kelly-Weeder S. Binge drinking and disordered eating in college students. J Am Acad Nurse Pract. 2011;23:33-41.

8. Peralta RL. Alcohol use and the fear of weight gain in college: reconciling two social norms. Gender Issues. 2002;20:23-42.

9. Giles SM, Champion H, Sutfin EL, McCoy TP, Wagoner $\mathrm{K}$. Calorie restriction on drinking days: an examination of drinking consequences among college students. $J$ Am Coll Health. 2009;57:603-609.

10. Burke SC, Cremeens J, Vail-Smith K, Woolsey C. Drunkorexia: calorie restriction prior to alcohol consumption among college freshmen. J Alcohol Drug Educ. 2010;54:17-34.

11. Barry AE, Piazza-Gardner AK. Drunkorexia: understanding the co-occurrence of alcohol consumption and eat- ing/exercise weight management behaviors. $J$ Am Coll Health 2012;60:236-243.

12. Piazza-Gardner AK, Barry AE. The weight-conscious drinker: expanding our understanding of the counterintuitive alcohol-physical activity relationship among college students. Am $J$ Health Educ. In press.

13. Bryant JB, Darkes J, Rahal C. College students' compensatory eating and behaviors in response to alcohol consumption. $J$ Am Coll Health. 2012;60:350-356.

14. Kershaw S. Starving themselves, cocktail in hand. New York Times. March 2, 2008. Available at: http://www.nytimes com/2008/03/02/fashion/02drunk.html?pagewanted=all. Accessed August 9, 2012.

15. Jennings A. Drunkorexia: alcohol mixes with eating disorders. $A B C$ News. October 21, 2010. Available at: http://abcnews.go.com/Health/drunkorexia-alcohol-mixes-eatingdisorders/story?id=11936398. Accessed August 9, 2012.

16. American College Health Association. American College Health Association-National College Health Assessment spring 2008 reference group data report. $J$ Am Coll Health. 2009;57:477-488.

17. Borsari B, Murphy JG, Barnett NP. Predictors of alcohol use during the first year of college: implications for prevention. Addict Behav. 2007;32:2062-2086.

18. Barry AE. Using theory-based constructs to explore the impact of Greek membership on alcohol-related beliefs and behaviors: a systematic review. J Am Coll Health. 2007;56:307-315.

19. Aires N, Selmer R, Thelle D. The validity of self-reported leisure time physical activity and its relationship to serum cholesterol, blood pressure and body mass index. A population based study of 332,182 men and women aged 40-42 years. Eur J Epidemiol. 2003;18:479-485.

20. Fang J, Wylie-Rosett J, Cohen HW, Kaplan RC, Alderman MH. Exercise, body mass index, caloric intake, and cardiovascular mortality. Am J Prev Med. 2003;25:283-289.

21. Kim DS, Kim HS, Cho Y, Cho SI. The effects of actual and perceived body weight on unhealthy weight control behaviors and depressed mood among adult women in Seoul, Korea. J Prev Med Public Health. 2008;41:323-30.

22. Kim DS, Cho Y, Cho SI, Lim IS. Body weight perception, unhealthy weight control behaviors, and suicidal ideation among Korean adolescents. J Sch Health. 2009;79:585-592.

23. Muthen B. Latent variable structural equation modeling with categorical data. J Econometr. 1983;22:48-65.

24. Muthen B, Kaplan D. A comparison of some methodologies for the factor analysis of non-normal Likert variables. Br J Math Stat Psychol. 1985;38:171-189.

25. Hu L, Bentler PM. Cutoff criteria for fit indexes in covariance structure analysis: conventional criteria versus new alternatives. Struct Equ Model. 1999;6:1-55.

26. Mueller RO, Hanckock GR. Structural equation modeling. In: Hancock GR, Mueller RO, eds. The Reviewer's Guide to Quantitative Methods in the Social Sciences. New York, NY: Routledge; 2010:371-382.

27. Strother E, Lemberg R, Stanford SC, Turberville D. Eating disorders in men: underdiagnosed, undertreated, and misunderstood. Eat Disord. 2012;20:346-355.

28. Krahn D, Piper D, King M, Kurth C, Moberg D. Dieting in sixth grade predicts alcohol use in ninth grade. $J$ Subst Abuse. 1996;8:293-301.

29. Stranges S, Notaro J, Freudenheim JL, et al. Alcohol drinking pattern and subjective health in a population-based study. Addiction. 2006;101:1265-1276.

30. Breslow RA, Smothers BA. Drinking patterns and body mass index in never smokers. Am J Epidemiol. 2005;161:369-376.

31. McCabe MP, Ricciardelli LA. Body image dissatisfaction among males across the lifespan: a review of past literature. $J P s y$ chosom Res. 2004;56:675-685. 
32. Tiggemann M, Martins Y, Kirkbride A. Oh to be lean and muscular: body image ideals in gay and heterosexual men. Psychol Men Masc. 2007;8:15-24.

33. Parks PSM, Read MH. Adolescent male athletes: body image, diet, and exercise. Adolescence. 1997;32:593602 .

34. Grabe S, Ward LM, Hyde JS. The role of the media in body image concerns among women: a meta-analysis of experimental and correlational studies. Psychol Bull. 2008;134:460476.

35. Thompson JK, Stice E. Thin-ideal internalization: mounting evidence for a new risk factor for body-image disturbance and eating pathology. Curr Dir Psychol Sci. 2001;10:181-183.

36. Hawkins N, Richards PS, Granley HM, Stein DM. The impact of exposure to the thin-ideal media image on women. Eat Disord. 2004;12:35-50.

37. Leit RA, Pope HG Jr, Gray JJ. Cultural expectations of muscularity in men: the evolution of Playgirl centerfolds. Int J Eat Disord. 2001;29:90-93.

38. Spitzer BL, Henderson KA, Zivian MT. Gender differences in population versus media body sizes: a comparison over 4 decades. Sex Roles. 1999;40:545-565.

39. Bergstrom RL, Neighbors C. Body image disturbance and the social norms approach: an integrative review of literature. $J$ Soc Clin Psychol. 2006;25:995-1020.

40. Dansky BS, Brewerton TD, Kilpatrick DG. Comorbidity of bulimia nervosa and alcohol use disorders: results from the National Women's Study. Int J Eat Disord. 2000;27:180-190.

41. O'Brien KM, Vincent NK. Psychiatric comorbidity in anorexia and bulimia nervosa: nature, prevalence, and causal relationships. Clin Psychol Rev. 2003;23:57-74.

42. Anderson DA, Simmons AM, Martens MP, Ferrier AG, Sheehy MJ. The relationship between disordered eating behavior and drinking motives in college-age women. Eat Behav. 2006;7:419-422.

43. Vickers KS, Patten CA, Bronars C, et al. Binge drinking in female college students: the association of physical activity, weight concern, and depressive symptoms. J Am Coll Health. 2004;53:133-140.
44. Nelson NC, Lust K, Story M, Ehlinger E. Alcohol use, eating patterns, and weight behaviors in a university population. Am J Health Behav. 2009;33:227-238.

45. Serdula MK, Mokdad AH, Williamson DF, Galuska DA, Mendlein JM, Heath GW. Prevalence of attempting weight loss and strategies for controlling weight. JAMA. 1999;282:1353-1358.

46. Kruger J, Galuska DA, Serdula MK, Jones DA. Attempting to lose weight: specific practices among U.S. adults. Am J Prev Med. 2004;26:402-406.

47. Weiss EC, Galuska DA, Khan LK, Serdula MK. Weightcontrol practices among U.S. Adults, 2001-2002. Am J Prev Med. 2006;31:18-24.

48. Millstein RA, Carlson SA, Fulton JE, et al. Relationships between body size satisfaction and weight control practices among U.S. adults. Medscape J Med. 2008;10:119.

49. Johnson F, Wardle J. Dietary restraint, body dissatisfaction, and psychological distress: a prospective analysis. J Abnorm Psychol. 2005;114:119-125.

50. Neumark-Sztainer D, Paxton SJ, Hannan PJ, Haines J, Story M. Does body satisfaction matter? Five-year longitudinal associations between body satisfaction and health behaviors in adolescent females and males. J Adolesc Health. 2006;39:244-251.

51. Markey CN, Markey PM. Relations between body image and dieting behaviors: an examination of gender differences. Sex Roles. 2005;53:519-530.

52. McCreary DR, Sasse DK. An exploration of the drive for muscularity in adolescent boys and girls. J Am Coll Health. 2000;48:297-304.

53. O'Dea J, Abraham S. Association between self-concept and body weight, gender, and pubertal development among male and female adolescents. Adolescence. 1999;34:69-79.

54. Stanford SC, Lemberg R. A clinical comparison of men and women on the Eating Disorder Inventory-3 (EDI-3) and the Eating Disorder Assessment for Men (EDAM). Eat Disord. 2012;20:379-394. 